\title{
Analysis of energy performance of school building stock in Rome
}

\author{
G. Moncada Lo Giudice, F. Fraticelli, F. Fornari \& C. Calice \\ University of Rome, Italy
}

\begin{abstract}
This paper aims to provide an assessment of a part of school building stock in Rome, through analysis of qualitative and quantitative data referred to a sample of 684 buildings used as primary school. This research designs a start point useful for administration to defining possible strategies and policies to reduce consumptions in this sector. The study has been performed by describing the characteristic of buildings related to construction age and comparing buildings' energy label with the thermal consumption metering, in order to obtain a model with a high level of objectivity and accuracy. The results show the necessity of a spread and deep intervention on school buildings for its high potential in energy and costs reduction.
\end{abstract}

Keywords: sustainability, energy label, energy, efficiency, schools.

\section{Introduction}

It has already been noted in other articles the importance of public school buildings' refurbishment intervention due to their capacity to spread a new style of living based on ecological responsibility. It is also necessary to strike a balance between cost reduction and high levels of comfort to influence student's performances $[1,2]$. These buildings also have a significant potential in energy savings, due to the high energy consumption generated by a low technological level in the building-plant system. This paper aims to analyze the quality of Rome's public school buildings in terms of energy consumption for space heating, as a first-step in evaluating possible intervention strategies for energy saving in this sector. 


\section{Methods}

The analysis has been focused on the city of Rome. According to Italian law, municipalities manage only school buildings used as primary and intermediate schools. Primary schools are kindergarten and elementary schools. This research was thus limited to primary schools in Rome, stock made of 1,296 structures and 13.5 million cubic meters.

It was available for the research three types of data:

- A quantitative type consists of number, type and dimension of buildings, updated on June 30, 2000 and provided by the City of Rome's Department for Assets Management.

- Energy label of municipally-owned buildings, which explains, combining qualitative and quantitative data, the quality in terms of energy demand for building's envelopes and plants, following the UNITS 11300 standards and method [3]. Although it is not possible to fully guarantee the homogeneity of this data, an high number of technicians were appointed by the different districts so these date are not fully guaranteed; however, the large amount of available data provided by City of Rome's Department For Assets Management regarding about 820 primary schools provides an excellent data base for each analysis and research which investigates the conditions of the entire stock.

- A third type of data, provided by the City of Rome's Department for Education on 382 buildings, are the efficiency of thermal plants installed in schools buildings measured by counters as heat transferred quarterly between 2003 and 2008. This database minimizes error rates because it shows actual measurements with ad high content of objectivity and reliability.

After the recognition of all data useful to describe the current situations, it has been considered the geographical and historical location of each school building, considering that often peripheral buildings are not ancient as buildings located in the city center. The age of the building is a very important indicator in order to classify the quality of the envelope. To help this subdivision, it has been taken into account the administrative division of the city in 19 administrative districts, numbered from I to XIX excluding XIV. Afterwards, all collected data has been filtered to remove those that were clearly wrong. As a result, buildings with an energy label considered in our analysis were reduced from 820 to 684 and buildings with consumption's metering from 382 to 271, buildings with both data available (energy label and consumption's metering) are 261. The data can be considered fully representative if we consider that we handle the energy labels for almost $50 \%$ of the total buildings and both energy label and consumption metering for the $20 \%$ of the total buildings (figure 1 ). 


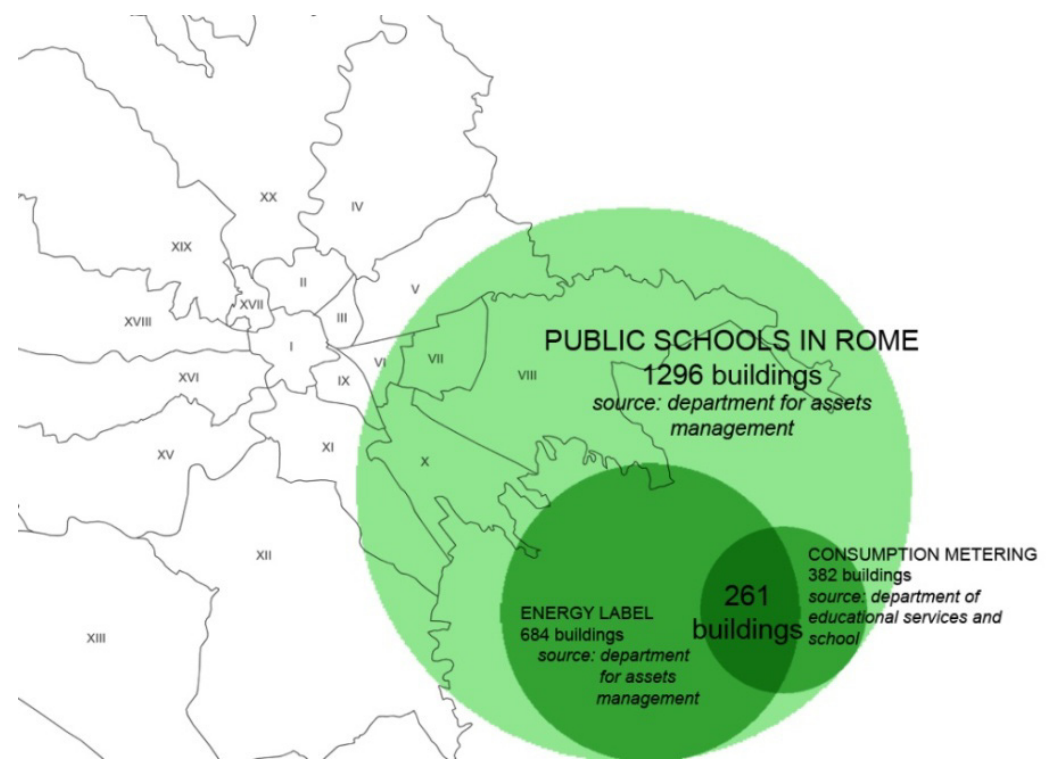

Figure 1: $\quad$ Map of Rome's 19 districts and description of the data available by different sources.

\section{Analysis on consistency of existing school buildings}

In the City of Rome, public schools have a cumulative volume of 13,518,925 cubic meters, with an average building volume of 10,431 cubic meters. Also, the buildings' location provides other important information. The peripheral districts

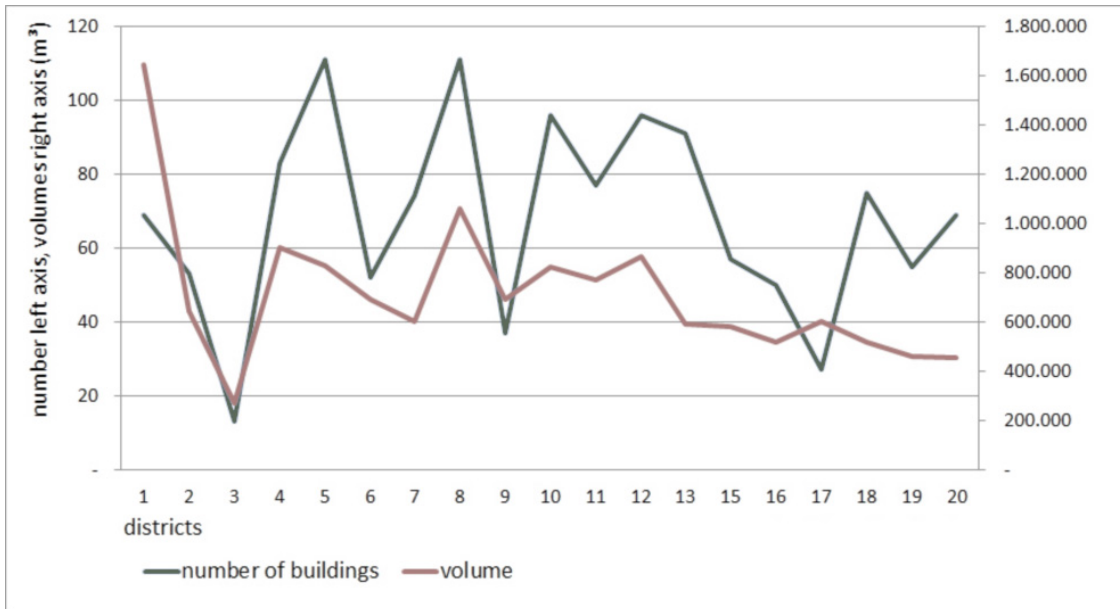

Figure 2: $\quad$ Existing buildings by district. 
IV, V, VIII, X, XI, XII and XIII are characterized by low density (lower average volume of building); central districts I, II, III, VI, IX and XVII, instead, are characterized by historic schools, with their large volumes and high ceiling. In the city center is concentrated the $68 \%$ of buildings exceeding 30,000 cubic meters.

Located in semi-central districts II, III, VI, IX, XIII and XVII are schools built between the unification of Italy and World War II. These buildings have very large volumes, flat roofs and large windows, load-bearing wall structures with floors in brick or concrete.

\section{Characterization of existing schools}

This classification by the date of construction can help in understanding the energy performance of these structures. This takes into consideration that constructions of the same period are characterized by a deep homogeneity in building technologies and that refurbishments are very rare in this sector. From the database, it follows how the average total volume per building of 10,341 cubic meters is congruent with the average of heated gross volume of about 9,500 cubic meters.

According to the considerations above, small volumes located in peripheral districts correspond to greater $\mathrm{S} / \mathrm{V}$ ratio and larger volume in central districts corresponds to lower $\mathrm{S} / \mathrm{V}$ ratio.

The historic buildings and those made during the beginning of the $20^{\text {th }}$ century are generally characterized by large volumes and a high ratio of connective and service spaces on classrooms, entailing a higher consumption of energy for their heating. In some cases the location of these buildings into an historic city involves a reduction of solar radiation which is useful for natural heating and lighting. Despite these shortcomings, the good state of maintenance of these building as consequence of their better quality in construction, and the thermal quality of walls related to the use of load-bearing walls, reduce energy consumption in these buildings and facilitate their refurbishment. On the other hand, a refurbishment intervention on these buildings will be limited by their historic value.

Modern buildings are characterized by thermal and acoustic performances absolutely not in line with current requirements of environmental comfort and energy management. This is due to a lower construction quality and a state of profound degradation that is particularly serious in the architectural envelope that frustrates the adoption of better technologies, as set by Italian D.M. of 18 December 1975 standards [4].

On the base of analysis and surveys carried out, we can provide some benchmarks: 
Table 1: $\quad$ Main technologies features of schools related to construction age.

\begin{tabular}{|c|c|c|c|c|c|c|c|}
\hline \multirow{2}{*}{$\begin{array}{c}\text { Construction } \\
\text { age }\end{array}$} & \multicolumn{4}{|c|}{ Building technologies } & \multicolumn{3}{|c|}{ U value (W/m²k) } \\
\cline { 2 - 8 } Before 1860 & $\begin{array}{c}\text { Number } \\
\text { of floors }\end{array}$ & $\begin{array}{c}\text { W } \\
\text { Windowed } \\
\text { surfaces }\end{array}$ & Roof & Wall & Roof & Windows \\
\hline & $\begin{array}{c}\text { Load- } \\
\text { bearing } \\
\text { walls }\end{array}$ & 3 & $20 \%$ & $\begin{array}{c}\text { Pitched } \\
\text { roof }\end{array}$ & 1 & 1.3 & 6 \\
\hline $1860-1940$ & $\begin{array}{c}\text { Load- } \\
\text { bearing } \\
\text { walls }\end{array}$ & 4 & $25 \%$ & Flat roof & 1.2 & 1.4 & 6 \\
\hline $1950-1990$ & $\begin{array}{c}\text { Reinforced } \\
\text { concrete }\end{array}$ & 2 & $30 \%$ & Flat roof & 1.4 & 1.4 & 4 \\
\hline
\end{tabular}

\section{Energy audit of modern and historical schools buildings}

After the above classification, the research aims to establish a relationship between age of construction and energy audit of envelopes. The energy performance indicator used to evaluate the efficiency of roofs, windows and walls is the Epienvas imposed by UNI-TS 11300 standards [3], which explains energy losses due to the building. As overall result, it have been calculated an average value of $18 \mathrm{kWh} /$ cubic meter per year (figure 3). This is a too high

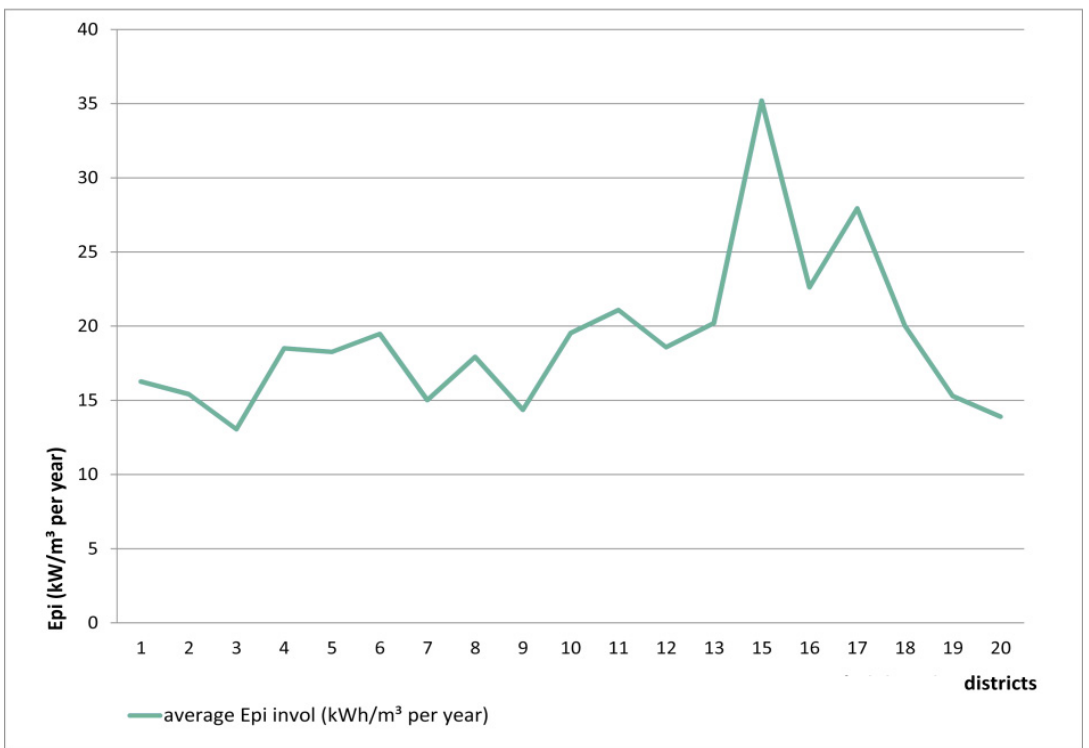

Figure 3: $\quad$ Epi envelope calculated for sample (sample: 684 buildings, data: energy label). 


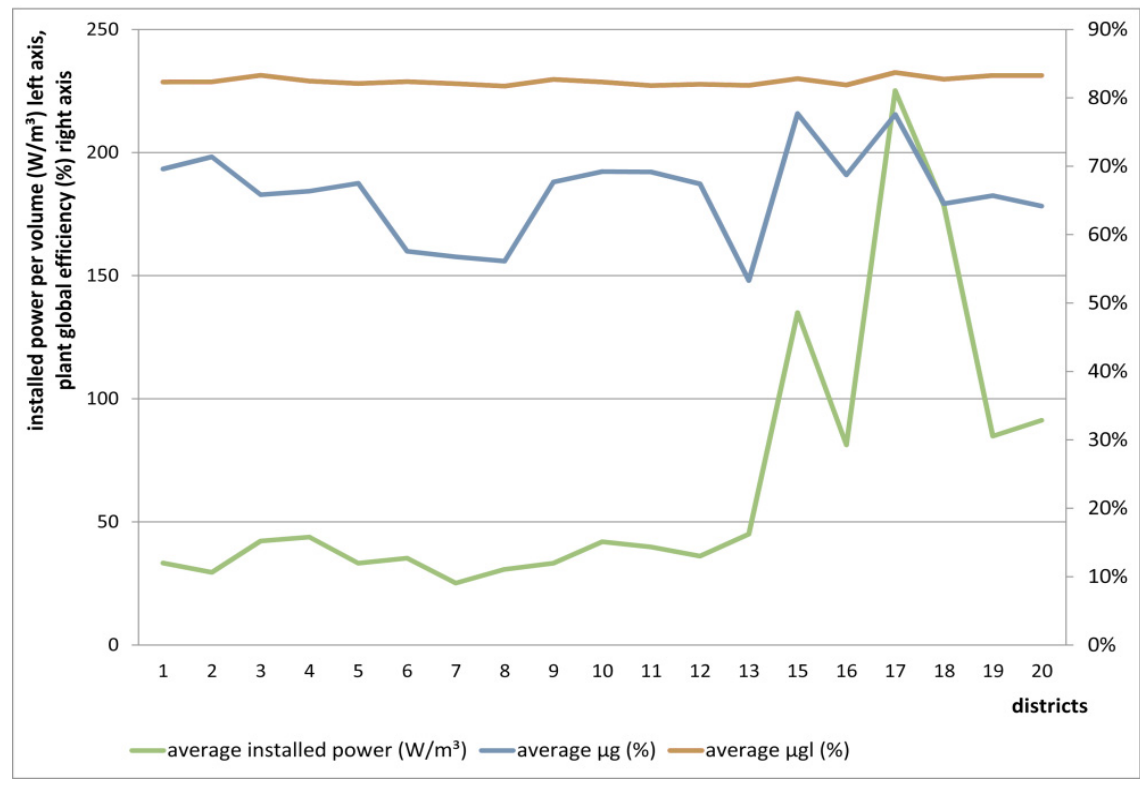

Figure 4: $\quad$ Energy performance of plants (sample: 684 buildings, data: energy label).

value, considering that about $10-12 \mathrm{kWh} /$ cubic meters per year as an acceptable standard [5] is absolutely not sufficient to guarantee good thermal performance for school buildings. Regarding thermal plants, (figure 4) it have been observed an average power installed is about $40 \mathrm{~W} /$ cubic meter with a percentage between 65 and $70 \%$ both in the case of modern and historic buildings.

The current situation needs retrofitting strategies for both envelopes and plants, diversified following specific features and cases.

\section{Compared analysis of consumptions}

To give actual valence to the above considerations, it have been analyzed heat transferred measured quarterly between 2003 and 2008 by counters.

To exclude any misunderstanding from now "theoretical consumption" is defined as the consumption calculated through UNI-TS 11300 standards [3] while "real consumption" will refer to measured consumption.

The trend of consumption in the last decade is quite uniform in all districts, with minimum value during the winter of 2006/07, one of the warmest winters in the last years.

In order to identify priority actions to improve energy efficiency, neglecting the different possible operating conditions, the research compares overall real consumption with Epi values derived from energy labels. The main differences between the two types of consumption are: 
- in energy label are not taken into account closing days (holidays, weekends, etc.) and opening hours, assuming that the heating system is working continuously 24 hours a day

- The internal temperature is not constant, but may change because of regulation systems

- Energy labels does not take into account the real state of maintenance of building envelopes, which can often influence the indoor comfort and air

Although the IAQ (Indoor Air Quality) control should not affect real consumption, because in reality the schools are not equipped with air conditioning systems, a high level of air changes may have influenced the sizing of the thermal plant and thus the final real consumption. DM 18 December 1975 in fact requires a high number of air changes, about 2.5-3 air changes per hour, depending on the type of school. Regarding theoretical consumption, UNI-TS 11330 calculation prescribes 1.5 air changes in the case of school buildings [3]. It is more likely to assume that certifiers have imposed a standard of 0.3 volumes/ hour, without specifying the actual requirements for ventilation of the classrooms, thus ensuring greater correspondence to the effective status of buildings. This parameter however, indicates how these buildings often fail to ensure a minimum necessary IAQ that is of crucial importance for their users' growth and learning [1,2] and how current levels of consumption are very unjustified.

The relation between measured consumption corrected in order to incorporate the losses of generation and the theoretical consumption is shown in figure 5 . The curves are:

- Epi corr1, theoretical consumption corrected in order to take into account the actual hours of use of structures.

- Epienv corr. theoretical consumption corrected in order to take into account the actual hours of use of structures, related to the building envelope, excluding thermal plant losses.

- $\quad$ Epienv corr. class $C$ that represents an average value of Epi inv for class C labeled buildings as reported in Dlgs 192/2005 [5].

The graph may show how school buildings consume more than they really need. The most likely cause is the absence of a control system that can fix internal temperature and minimize waste.

In the end, we can consider the area between the average measured consumption and the average Epi curve, as the potential savings (35-40\%) achievable simply by adopting responsible behaviors and with the use of efficient regulation systems. The area between the curves Epi corr1 and Epienvcorr as the potential energy saving achievable through interventions on thermal plants (30-35\%) and the area between Epienvcorr and Epienvcorr class $\mathrm{C}$ as the potential energy saving achievable through interventions on buildings envelope (45-50\%). Regarding building plants, we will then need to consider whether it is more convenient to make stronger or lighter interventions according to a cost/benefits analysis. Thermal plants instead, considering the less 
invasive intervention, would be certainly more advantageous from the point of view of a simple cost/benefit analysis.

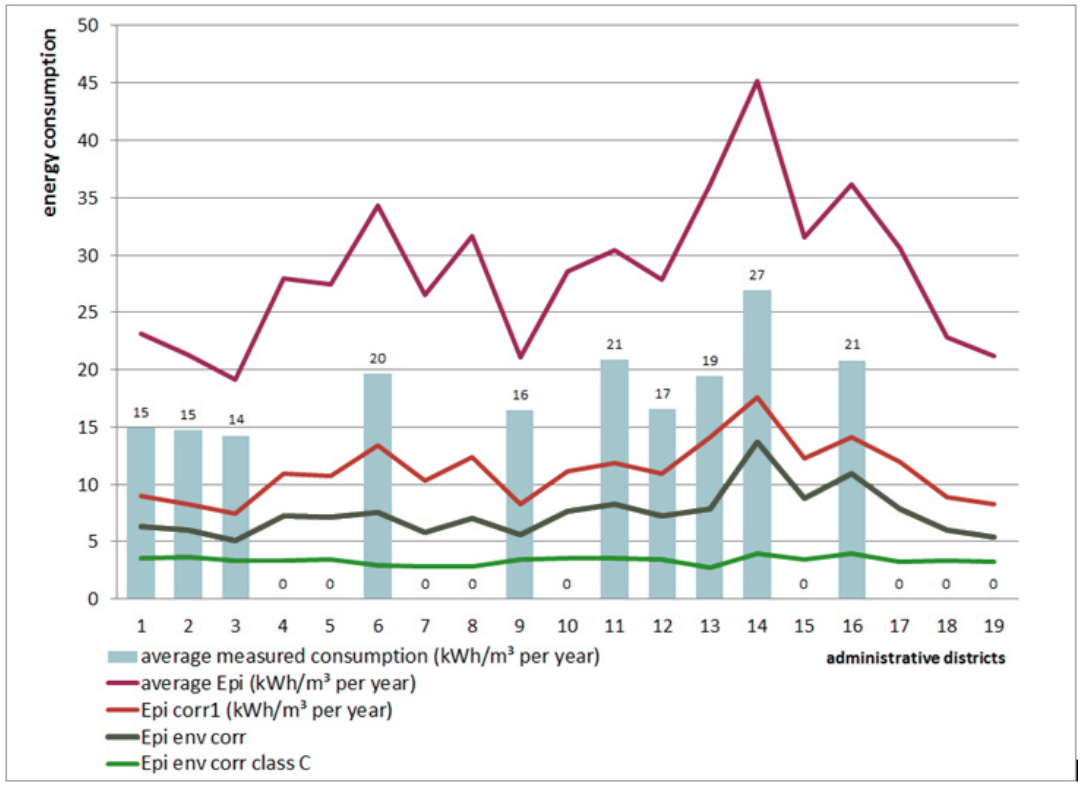

Figure 5: Comparison between theoretical and real consumption.

\section{Conclusions}

The analysis shows the urgency of a strong action of refurbishment for public schools in Rome because of the high level of energy consumption that have reached out of control levels.

Inefficiencies in the management of buildings and plants can be easily overcome with simple and low cost actions, following strategies and energy policies with high benefits for the entire building public stock. The results potentially available, as shown in the analysis, are very significant and can result in considerable advantages in terms of energy saving, indoor comfort and improved quality of the buildings. A not quantifiable indicator is the wellness of users, mostly children, who can live a more comfortable and healthy schools, while administrations can start a best practice in the management of public stock and city regeneration.

\section{References}

[1] De Santoli L., Fraticelli F., Fornari F., Planning the integration of new technologies for sustainability: case study of a school building's restoration project in Rome. ECO-ARCHITECTURE III, Harmonization between 
architecture and nature WIT Press, 2010, pages 423-434, ISBN 9781845644307.

[2] Wargocki P., Wyon D.P., Effects of HVAC on student performance, ASHRAE journal, 2006.

[3] UNI TS 11300-1:2008, Prestazioni energetiche degli edifici - Parte 1: Determinazione del fabbisogno di energia termica dell'edificio per la climatizzazione estiva ed invernale (Evaluation of energyneed for spaceheating and cooling); UNI TS 11300-2:2008, Determinazione del fabbisogno di energia primaria e dei rendimenti per la climatizzazione invernale e per la produzione di acqua calda sanitaria (Evaluation of primary Energy need and of system efficiencies for spaceheating and domestic hot water production).

[4] Decreto Ministeriale 18/12/1975, Norme tecniche aggiornate relative all'edilizia scolastica, ivi compresi gli indici di funzionalità didattica, edilizia ed urbanistica, da osservarsi nella esecuzione di opere di edilizia scolastica (Updatedtechnicalstandards for schoolbuildings).

[5] D.lgs 192/2005, Attuazione della direttiva 2002/91/CE relativa al rendimento energetico nell'edilizia (Execution of 2002/91/EC Directive on energy performance of buildings). 